\title{
Update on Pediatric non-Postoperative Junctional Ectopic Tachycardia.
}

Maldonado Sebastian $^{1 *}$, Albaca Guadalupe ${ }^{1}$, Lafuente María Victoria ${ }^{1}$, Benjamin Monica ${ }^{1}$, Lopez Jinete Darues ${ }^{1}$, Guerchicoff Marianna $^{2}$, Sciegata Alberto ${ }^{1}$

${ }^{1}$ Garrahan Children Hospital, Buenos Aires, Argentina

${ }^{2}$ Buenos Aires Italian Hospital, Argentina

*Corresponding author: Sebastián Maldonado, Garrahan Children Hospital, Buenos Aires, Argentina. E-mail: docseba79@hotmail.com Received date: October 28, 2019; Accepted date: November 12, 2019; Published date: November 19,2019

Citation: Sebastian M., Guadalupe A., Lafuente M Victoria., Monica B., Lopez J Darues. et al. (2019) Update on Pediatric non-Postoperative Junctional Ectopic Tachycardia. J Clinical Cardiology and Cardiovascular Interventions, 2(3); DOI:10.31579/2641-0419/025

Copyright: ( 2019 Sebastián Maldonado. This is an open access article distributed under the Creative Commons Attribution License, which permits unrestricted use, distribution, and reproduction in any medium, provided the original work is properly cited.
Abstract
Junctional ectopic tachycardia (JET) is a rare supraventricular tachycardia more frequently seen in pediatric patients which is associated with high morbidity and mortality without an adequate treatment. Its treatment often requires multiple drugs for arrhythmia control and, in some cases, a cryoablation is indicated. Some patients may revert to sinus rhythm spontaneously after long periods on antiarrhythmic drug.
Currently, the arrhythmia prognosis has improved significantly since cryoablation development and the implementation of a more aggressive pharmacological treatment strategy.
The purpose of this review is to describe the natural history of idiopathic JET and treatment advances.
Keywords: junctional ectopic tachycardia; ablation, cryoablation; Junctional tachycardia; congenital junctional tachycardia

\section{Abbreviations:}

JET: Junctional Ectopic Tachycardia

AV: atrio-ventricular

VA: ventriculo-atrial

INRT: intra-nodal reentrant tachycardia

\section{Introduction}

Non post-operative junctional ectopic tachycardia is an arrhythmia first described by Coumel in 1976 [1]. JET is a supraventricular tachycardia

\section{Appendix}

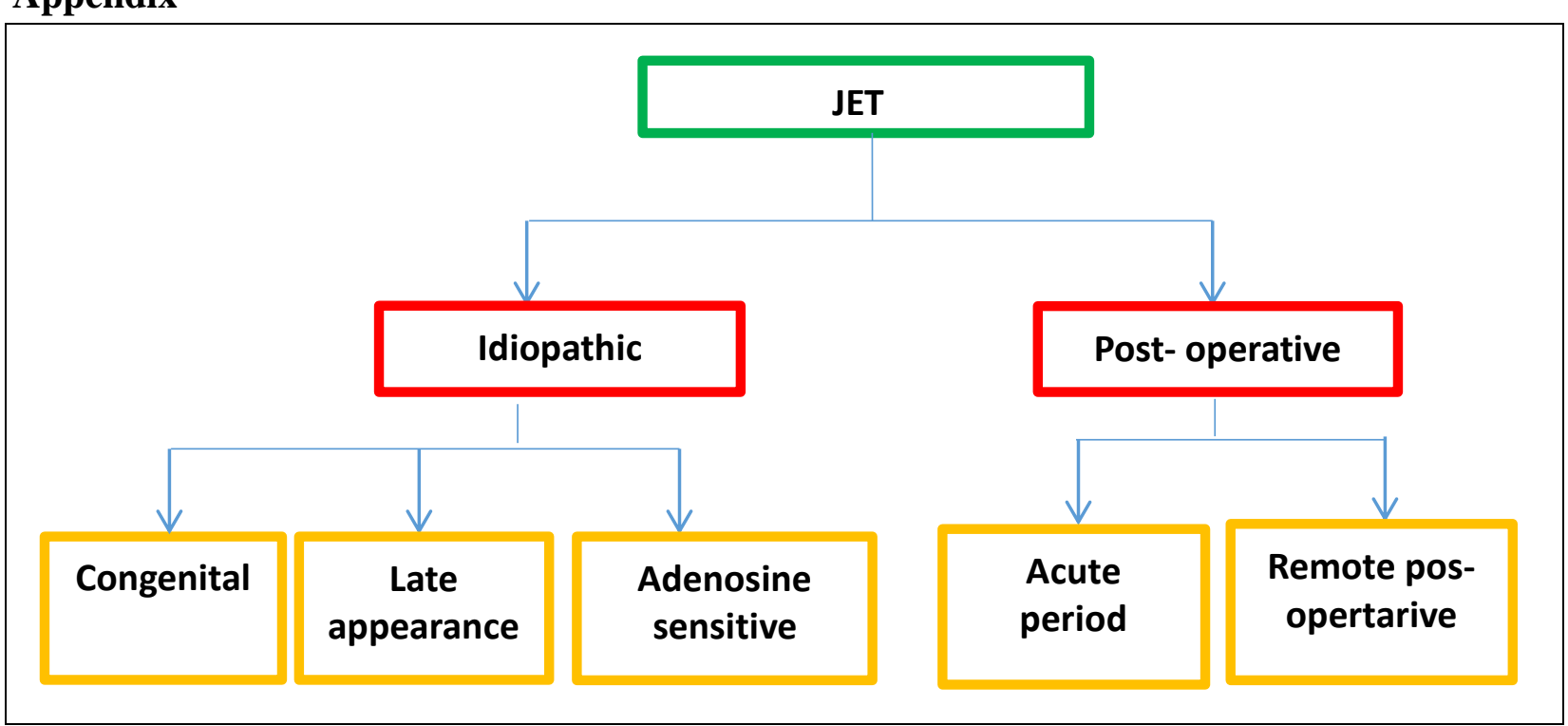

Auctores Publishing - Volume 2(3)-025 www.auctoresonline.org Page - 1 found in pediatric patients and requires multiple drugs to maintain arrhythmia control [2]. JET is associated with high mortality without drug treatment and, in certain patients, cryoablation is required [2-4]. Development and advances in ablation techniques such as cryoablation and 3D mapping may cure JET with an acceptable rate of success and low complications.

Some studies have demonstrated the existence of cases with spontaneous remission after long periods of treatment with antiarrhythmic drugs $[4,5]$.

\section{JET Classification}

Different types of JET have been described (Figure 1). 

congenital JET diagnose is done within the first year of life, late onset JET usually appears after the third year of life. Both types of idiopathic JET can be associated with congenital heart disease and adenosine-sensitive JET that can be observed in some complex congenital cardiopathies. Post-operative JET is most frequently seen within the first $24-72$ hours, less commonly can appear in remote post-operative stage.

JET: Junctional Ectopic Tachycardia

We can classify JET into 2 groups. On one side those related to cardiac post-operative surgery, mainly those in which the surgery compromises the heart crux. Inside this group, the most frequent form appears during the early post-operative period, generally within the first 24-72 hours being less likely to find in the long term follow up [6-9]. The second group is idiopathic JET, which is divided into 2 subgroups: congenital JET which is the most prevalent and is diagnosed within the first year of life. Some of them can be detected on fetal stage [2-4]. The second form is late onset JET, which usually appears after the third year of life. Both types of idiopathic JET can be associated with congenital heart disease [4]. A third special form of JET, which is adenosine-sensitive and unrelated to postoperative cardiac surgery, can be observed in some complex congenital cardiomyopathies such as univentricular physiology, especially in patients with disbalanced AV defect, heterotaxy syndrome and corrected transposition of great vessels or, sometimes, even in patients without any type of structural cardiomyopathy [10].

\section{Electrophysiologic mechanism}

The most prevalent mechanism is an increase in automatism of muscular focus that can be found around the atrio - ventricular node (AV node) [11,12]. JET is generally not induced with atrial stimulation; it cannot be reverted by overstimulation and it can be provoked with isoproterenol infusion. There are some cases in which mechanism is triggered activity since, to be induced, the use of isoproterenol with atrial stimulation is required, and it can be reverted to sinus rhythm with adenosine administration [10].

In some patients, the existence of families with congenital JET suggests a genetic origin of the arrhythmia [2-5]. Xi et al reported a family of 6 members with progressive cardiac conduction defect; two of them also developed congenital JET. Whole exome sequencing was made and a Gen TNNI3K mutation was identified. This gene codifies a Cardiac Troponin linked to MAP kinase, which has been associated with dilated cardiomyopathy, electric conduction disturbance and atrial tachycardia [13].

\section{Clinical manifestations}

Congenital JET usually presents as an incessant irregular tachycardia, with a heart rate range between 140 and $370 \mathrm{bpm}$. In Maldonado et al, the average frequency was $192 \mathrm{bpm}$ [2,3]. High heart rate during long periods of time, irregular rhythm, lack of AV synchrony and low contractile myocardial reserve favors the development of severe dilated cardiomyopathy and heart failure in newborns, sometimes leading to cardiogenic shock [2-5].

Villain et al. reported an incidence of $61.5 \%$ with heart failure and shortening fraction reduction [2]. Similar rates were observed in Sarubbi 's work in which $44.4 \%$ presented heart failure and $66 \%$ ventricular systolic dysfunction [4]. In Maldonado et al, among 23 patients with congenital JET, $45.5 \%$ had shortening fraction lower than $30 \%$, and
$62.5 \%$ were admitted into intensive care due to heart failure [5]. Some cases during fetal life have been reported. [14]

Collins et al included 94 patients with idiopathic JET, 16 patients (17\%) were diagnosed during the fetal life, 4 of them presented hydrops. The same incidence was shown in Villain et al job, in which $15.3 \%$ of the cases were diagnosed in fetal period, all of them with hydrops [2,3]. In idiopathic JET of late onset, the most frequent form of presentation was palpitations. The incidence of tachycardia-induced cardiomyopathy is very low. In our experience, we have 9 patients with late onset JET, and none of them has developed ventricular dysfunction [5].

There are reports of sporadic cases that can develop complete AV block over time [15,16]. In Collins et al work, 3 patients $(3,2 \%)$ developed AV complete block and a pacemaker was implanted. In Villain et al job, only one patient showed complete AV block (3,8\%). In Sarubbi et al series, as well as in our registry, no case of complete AV block was diagnosed [24]. Another less frequent clinical presentation is dilated cardiomyopathy not related to tachycardia. In our registry, there were 2 male siblings with congenital JET, both treated with amiodarone and atenolol. A successful cryoablation of the ectopic focus was performed in one of them. In the other patient, JET rate slowed down over time, evolving into an accelerated nodal rhythm, even without antiarrhythmic drugs. Both patients, despite having their arrhythmia under control, developed a severe dilated cardiomyopathy; one of them had ventricular fibrillation followed by sudden death, while an implantable defibrillator was indicated to the other patient as primary prevention [5].

Congenital heart disease association is less likely to be found, being it more frequent in patients with single ventricle, corrected transposition of great vessels, heterotaxy syndrome and AV canal defect [10]. Adenosine - sensitive JET is the most prevalent form in these cases. In our experience, a patient with corrected transposition of great vessels, without any surgical treatment, presented an adenosine-sensitive JET refractory to drugs, requiring cryoablation.

Some series show a familiar presentation above $50 \%$. However, in our series only $8,6 \%$ presented family history with JET.

\section{Diagnosis}

JET diagnosis is mainly electrocardiographic. It is a narrow QRS tachycardia, usually irregular, with AV dissociation. Sporadic sinus captures can be observed, as well as cool down- warm up phenomenon, with a heart rate average above the 95 percentile according to age. (Figure 2) They can sporadically show a 1:1 ventricular atrial conduction. In our work, out of 23 patients with congenital JET, $70 \%$ of them were incessant and $92.4 \%$ showed VA dissociation, unlike Collins et al report in which VA dissociation could only be found in $56 \%$ of Idiopathic JET [3;5]. As it is a tachycardia with very specific characteristics, it is easy to be diagnosed. However, in those variants with 1:1 retro-conduction, a differential diagnosis with nodal reentrant tachycardia has to be made [17]. 


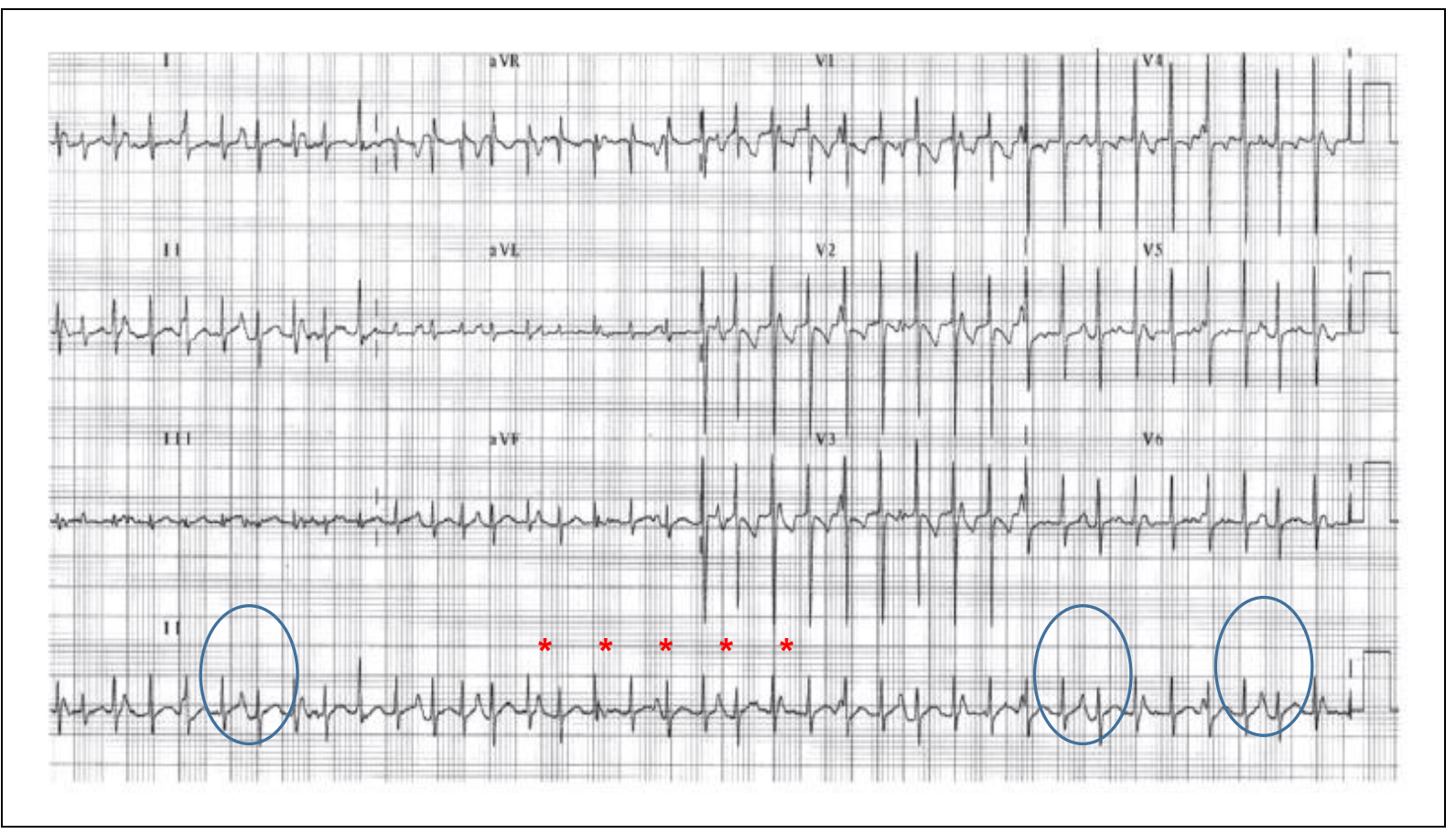

\section{Figure 2. JET Electrocardiogram.}

- $\quad$ Narrow QRS tachycardia, usually irregular, with AV dissociation (*).

- $\quad$ Sporadic sinus captures can be observed (blue circle)

A Prenatal JET diagnosis can be given with fetal doppler echocardiogram, using a cava / aorta window. The presence of ventricular activation interval faster than atrial and dissociated is characteristic of JET, being a possible differential diagnosis ventricular tachycardia [18].

\section{Mortality}

Initial works in congenital JET reported a high mortality. In Villain et al series, the incidence of mortality was $34 \%$, being the cardiogenic shock and the high heart rate the main causes of death [2]. However, recent studies have demonstrated that using more aggressive pharmacological strategies, and arrhythmia ablation in some cases, significantly have improved JET prognosis. In Collins work, the mortality rate was $4 \%$, being the main cause heart failure secondary to tachycardia [3] In Sarubbi et al job, no death cases were shown, while in our registry there was only one case $(4,3 \%)$ with sudden death due to ventricular fibrillation secondary to severe dilated cardiomyopathy (Figure 3) [4;5]

\begin{tabular}{|c|c|c|c|c|}
\hline Variables & Villain et al (1990) & $\begin{array}{l}\text { Sarubbi et al } \\
\text { (2002) }\end{array}$ & Collins et al (2009) & $\begin{array}{l}\text { Maldonado et al } \\
\text { (2018) }\end{array}$ \\
\hline $\mathrm{N}^{\circ}$ Pts & 26 & 9 & 92 & 31 \\
\hline $\begin{array}{l}\text { Age at } \\
\text { presentation (yrs) }\end{array}$ & 1 & 3.8 & 9.6 & 2 \\
\hline Heart Failure (\%) & 3.8 & 44.4 & 16 & 62,5 \\
\hline $\begin{array}{l}\text { Tachycardia } \\
\text { induced DCM (\%) }\end{array}$ & 9.6 & 66.6 & Not informed & 42,8 \\
\hline RF ablation (\%) & 1,5 & & 18 & 0 \\
\hline Cryoablation (\%) & 2 & & 27.6 & 19,3 \\
\hline Pacemaker (\%) & 23 & 0 & 14 & 0 \\
\hline Follow up (years) & 6.1 & 12,4 & 4.5 & 8.8 \\
\hline Death (\%) & 34 & 0 & 4 & 0 * \\
\hline Age at SR (years) & 3,6 (range: $0,5-8$ ) & & 3 (range $0,3-20$ ) & $9,31+/-5,1$ \\
\hline SR rate (\%) & 23 & 0 & 33.1 & 51.6 \\
\hline
\end{tabular}




\section{Figure 3: Published studies with idiopathic JET.}

JET: Junctional Ectopic Tachycardia, RF: radiofrequency, abl: ablation, SR: spontaneous remission

* In our study published in 2018, there was no death, but 6 months later one patient with dilated cardiomyopathy presented sudden death due to ventricular fibrillation.

\section{Spontaneous remission}

Natural history of congenital JET patients may have a different course. Some patients may evolve to a spontaneous resolution after long periods of pharmacological treatment. Some of them begin with a drop in the heart rate of the ectopic focus, reaching a normal range according to age, even without antiarrhythmic drugs. Finally, they show longer periods of sinus rhythm, until complete recovery. In our work, $15 \%$ of congenital JET patients presented spontaneous resolution at the age of 4 and $62,5 \%$ at 10 years [5]. Collins et al reported $22,3 \%$ patients with spontaneous remission to sinus rhythm and $11,7 \%$ evolved towards an accelerated nodal rhythm with controlled heart rate without pharmacological therapy [3]. The presence of an accelerated nodal rhythm without antiarrhythmic drugs, in our experience, is an early sign of congenital JET spontaneous resolution. In our series of 8 patients with late JET onset, all of them required cryoablation due to the symptoms.

\section{Pharmacological treatment}

Initial approach in congenital variant is pharmacological therapy. Many studies have evaluated different antiarrhythmic drugs: digoxine [2,3], propafenone [19], flecainide [20,21] sotalol, beta blockers and amiodarone [2]. Usually, the initial response to treatment is a heart rate slow down, often requiring more than one drug [2-5].

Amiodarone has demonstrated to be the most effective drug. In our job, $17.3 \%$ was used as a single drug and combined with beta blockers in $69.5 \%$, getting arrhythmia control in $86.8 \%$ of the patients [5]. Despite Amiodarone side effects, the incidence in patients younger than 5 years old is lower than the reported among adult population. In our work, only 2 out of 23 patients treated with Amiodarone developed a TSH level increase without clinical manifestation, which reverted after drug discontinuation. One patient showed corneal deposits without visual compromise (13.3\%) [5].Unlike congenital JET, patients with late onset JET required a less frequent use of combined drugs. In our experience, $87.5 \%$ of patients were controlled by using only one antiarrhythmic agent [5].
Recent studies reported congenital JET refractoriness to the combination of amiodarone and beta blockers, in which beta blockers were replaced by Ivabradine, an IF channel blocker present in cells with automatism, reaching sinus rhythm or an adequate heart rate control in all cases [2125]. There are also reports of postoperative JET with positive results $[26,27]$. This drug has the advantage of giving an antiarrhythmic effect without affecting inotropism, with a low rate of side effects. In our experience, we only used it in one patient with congenital JET refractory to amiodarone and atenolol. Ivabradine allowed an adequate rate control of the arrhythmia, and due to significant drop in heart rate Amiodarone, it could be discontinued.

Nifekalant and Vernakalant are fast potassium currents ( $\mathrm{IKr}$ ) blockers that are located mainly in the atrial tissue, increasing refractory period. Aoki et al published a report of 2 patients with congenital JET refractory to multiple drugs, including amiodarone, in which patients were treated with Nikefelant, achieving arrhythmia control in both cases [28].

\section{Non pharmacological treatment}

Development of invasive procedures for treating arrhythmias lead to positive results as many of them could be treated without the need of AV node ablation and pacemaker implantation. The first studies published about JET ablation were with radiofrequency therapy. Although in most cases it could be ablated successfully. However, as the arrhythmogenic substrate is close to specialized cardiac conduction system, the risk of complete AV block is also higher than in other arrhythmia ablations. In Collins et al registry, $18 \%$ of JET patients in whom radiofrequency ablation was performed presented complete $\mathrm{AV}$ block due to the procedure [3]. In the last decades, a new technique of ablation using cold, known as cryoablation, has been developed. Cryoablation generates small regular lesions with no endothelium disruption, allowing application at intermediate temperatures of $-30^{\circ} \mathrm{C}$ (cryothermal mapping), which generates reversible lesions, helping to avoid an AV node or HiS damage. When the ectopic focus is eliminated and no conduction system disturbance is seen, temperature is reduced to $-80^{\circ} \mathrm{C}$ to generate an irreversible lesion. Generally a double freeze-thaw applications of 240 to 480 seconds are performed (figure 4).
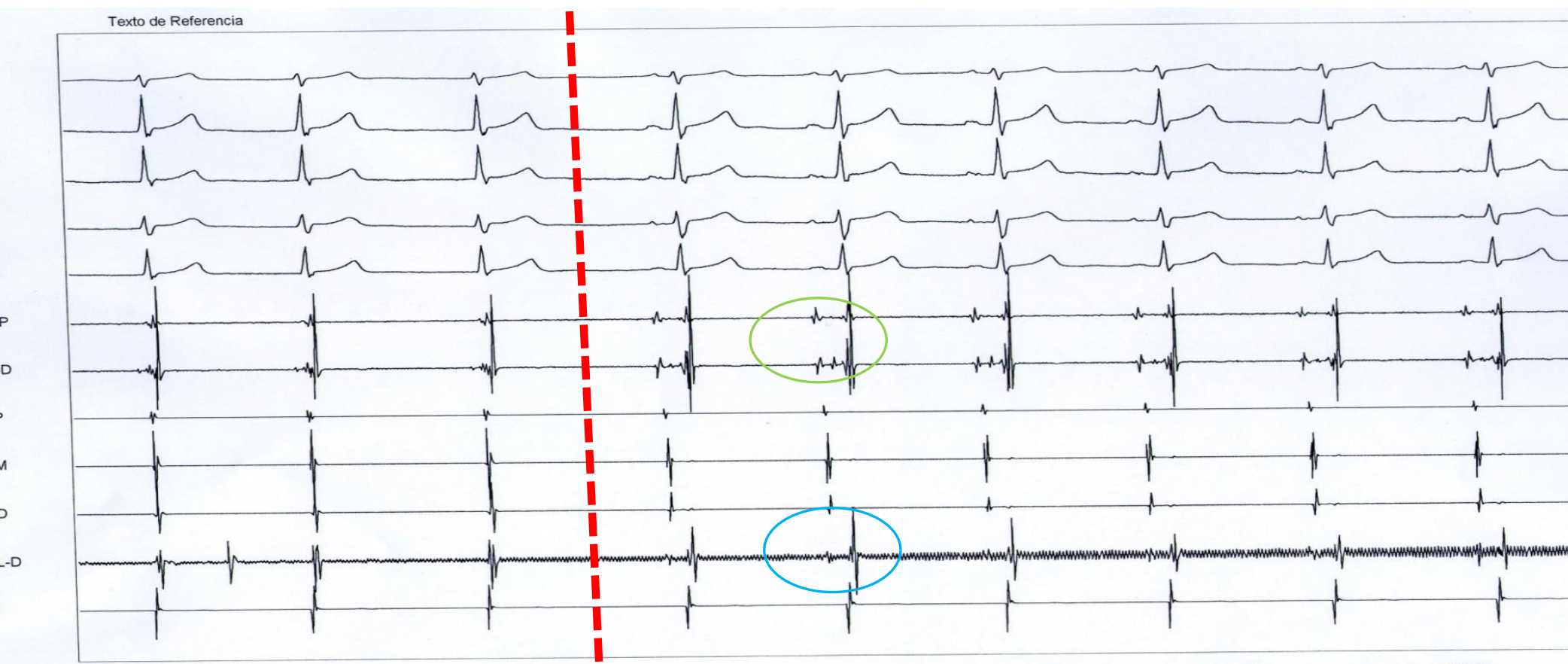

Est 00000271
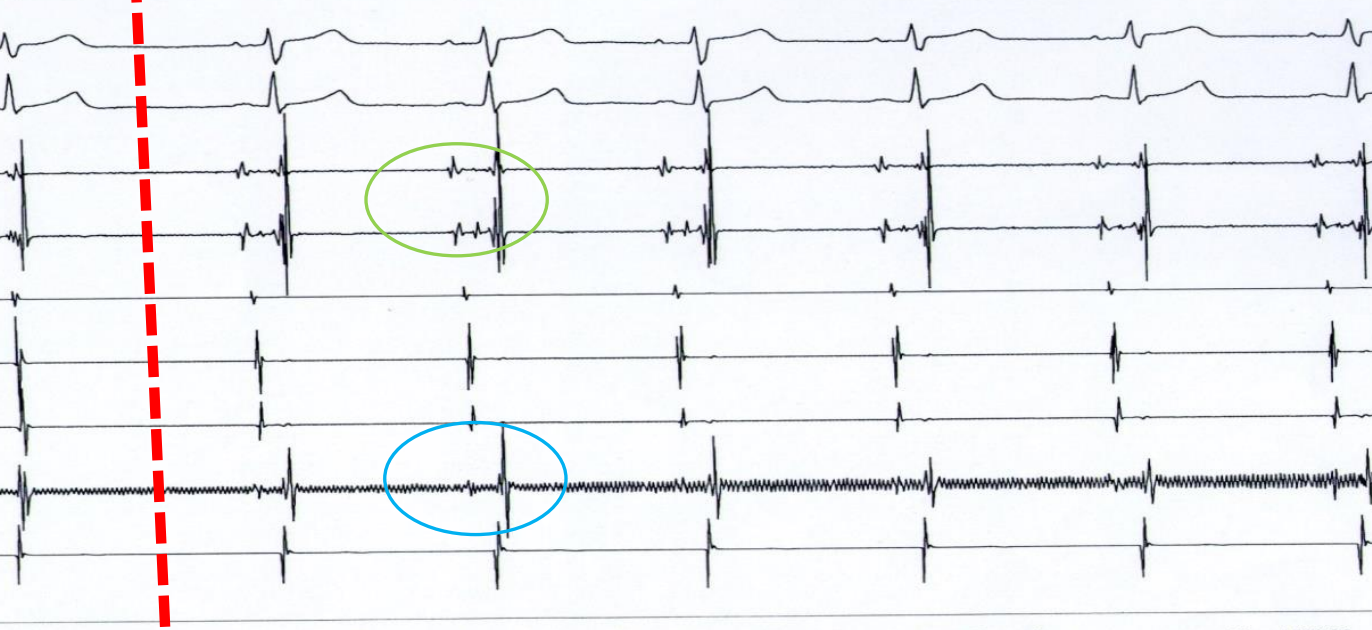

Auctores Publishing - Volume 2(3)-025 www.auctoresonline.org Page - 4 
Figure 4: Cryoablation

Tracings are ECG leads I,II, III, V1 , V6, and intracardiac electrograms recorded from CS 7-8 to CS 3-4, right ventricular apex (RVA), distal pairs of the

ablation catheter. The first 3 beats a nodal tachycardia with 1: 1 VA response is observed, an artifact in ablation is observed due to cryomapping. 4 beat, JET stop, and sinus rhythm restore.

JET: Junctional Ectopic Tachycardia, SCP: proximal coronary sinus SCM: middle coronary sinus, SCD: distal coronary sinus.

Cryoablation reduced the risk of AV block to almost zero [3,5,29]. Ablation indication depends on many factors such as: weight, pharmacological treatment response, hemodynamic commitment, side effects, etc. In Pierick et al series, cryoablation was performed in 13 patients, being able to eliminate the focus in $84,6 \%$ of them [29]. Collins et al reported 27 patients that required a cryoablation, resulting in a primary success of $85 \%$ and a recurrence of $13 \%$, while non post- ablation complications were described [3]. In our series, 12 patients went through 15 cryoablations and the success rate at the first procedure was of $91.7 \%$ with a recurrence of $25 \%$. The success rate after a second procedure reached $91.7 \%$ without recurrence and without complications [5]. Although the main goal of cryoablation is to eliminate the ectopic focus, in all the cryoablation published series, there is a subgroup of patients in which the focus cannot be completely eliminated. However, during postablation follow-up, these patients remain with nodal rhythm with acceptable heart rates, without the need of antiarrhythmic treatment and finally evolving towards permanent sinus rhythm [3,5,29,30]

\section{Differential diagnosis}

Differential diagnosis will depend on ventriculo-atrial (VA) conduction. If there is a VA relation 1:1, the main differential diagnosis to be made is with Intranodal Reentrant Tachycardia (INRT) since both of them show retro-conduction through the fast nodal pathway, generating a similar electrocardiogram. However, electrophysiological mechanism in INRT is reentrant, while in JET it is usually automatic or by triggered activity and all the electrophysiological maneuvers to distinguish one from another are based on this difference.

Wang et al described a maneuver which consists of performing a brief over atrial stimulation $30 \mathrm{~ms}$ faster than the tachycardia cycle length and evaluating the difference between the last entrainment VA interval (VAp) and the tachycardia VA interval (VAt). In patients with INRT, since the AV node is part of the circuit, the difference between the 2 intervals is similar, all patients with INRT had values less than $22,5 \mathrm{~ms}$, whereas JET patients had more than 294, $9 \mathrm{~ms}$ in all cases [31].

Srivathsan et al suggested entraining tachycardia from the base of the right ventricle and measuring delta HA between the last entrained beat and the one of the tachycardia. A delta HA $>0 \mathrm{~ms}$ was seen more frequently in JET patients (sensitivity of $89 \%$ and specificity of $83 \%$ ) [32].
Padanilam et al mentioned the use of atrial extra-stimulus during tachycardia and to evaluate the effect on His activation. There are 2 moments in which the maneuver can be done: an extra stimulus given in a His refractory period, if His electrogram is advanced and the arrhythmia is an INRT, since the only way to obtain that response is by the existence of a nodal slow pathway, whereas if the next $\mathrm{HH}$ interval does not change its cycle, it is more likely to be a JET. The second moment in which extrastimulus can be given is when His is permeable. If His is advanced and tachycardia is terminated, the arrhythmia is more likely to be an INRT, since the anterograde activation of the nodal fast pathway does not allow to be activated in a retrograde way as a result of being in a refractory period. If tachycardia continues, it is more likely to be JET since the nodal fast pathway is not a crucial part of the circuit [33].

Finally, Fan et al suggested entraining tachycardia from the atria $30 \mathrm{~ms}$ faster than the tachycardia cycle length, if tachycardia persists when the stimulation is stopped and the response obtained is AHHA, the tachycardia is a JET in $100 \%$ of the cases, whereas an AHA response is observed in all patients with INRT [34].

In JET patients with VA dissociation, differential diagnosis is with nodofascicular orthodromic tachycardia, whose mechanism is reentrant. This tachycardia, unlike the JET, can be provoked with atrial or ventricular stimulation; it can also develop QRS pre-excited with rapid atrial stimulation, present a variation of the cycle tachycardia length with the development of bundle branch block, and stop the tachycardia or the advancement of His potential, with an extra-stimulus on His refractory [35].

\section{JET location}

With regards to ectopic focus location in JET, there are differences among published studies (figure.3). In Law et al work, cryoablation was performed in 6 patients; in 4 of them the focus was located in the upper third of the Koch triangle, near the His [30], whereas in the registry of Pierrick et al the focus location was: 4 in the posteroseptal, near coronary sinus ostium, 4 in the low middle septal, over coronary sinus ostium, 4 in high middle septal area and 2 in the antero-septal near His [29]. In our series of 13 patients with JET who went through cryoablation, the location was: right posteroseptal in 2 patients, 3 in low middle septal, 4 in high middle septal and 3 in anteroseptal, near His (figure 5) [5] 


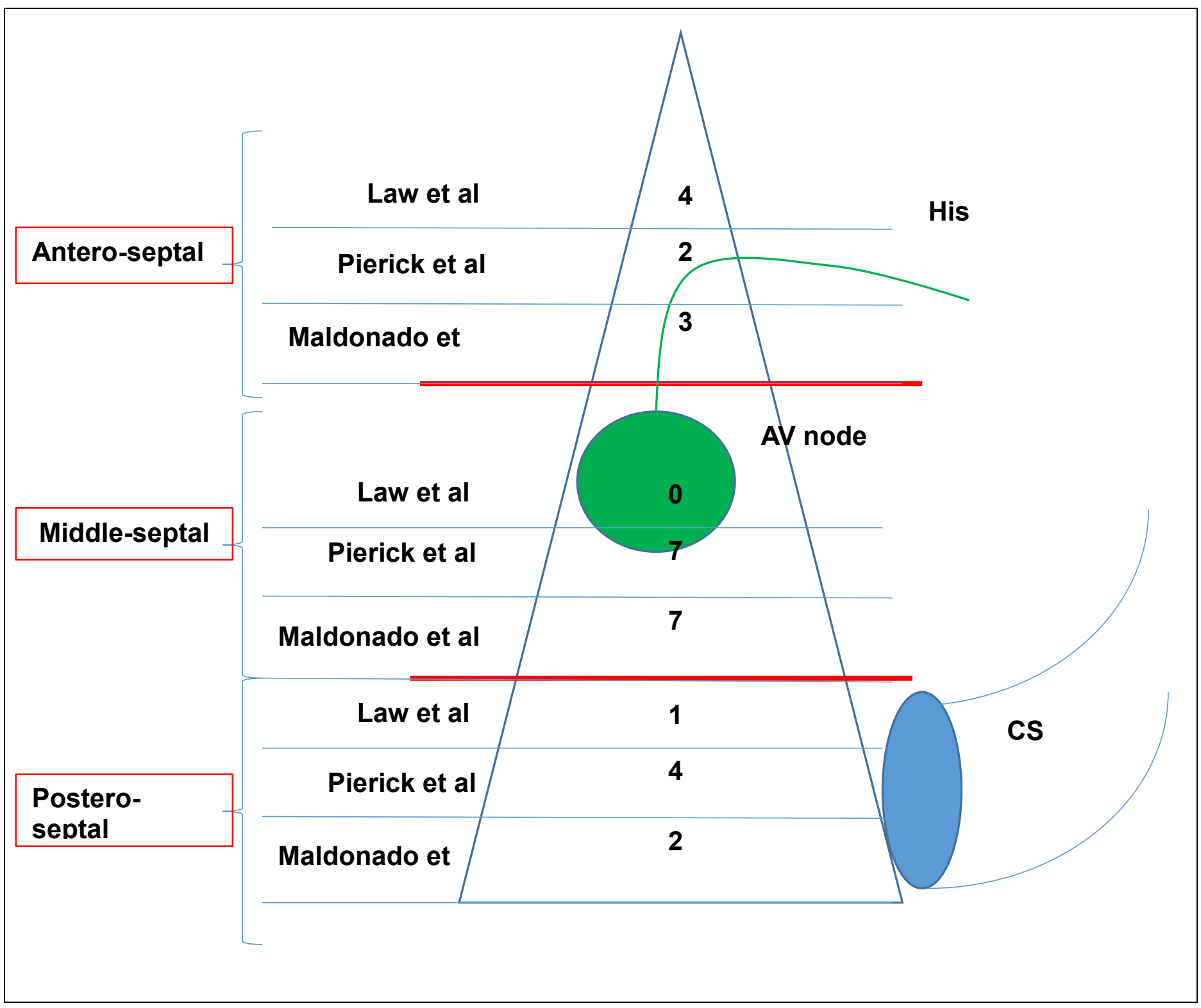

Figure 5: Ectopic focus location in JET: schematic representation of Koch Triangle, divided in 3 regions (anterior, middle and posterior septal). In each line, figures the location obtain in Maldonado, Pierick and Law works.

JET: Junctional Ectopic Tachycardia, CS: coronary sinus, AV atrio-ventricular

As Pierrick work, in our experience, the focus location in the lower $2 / 3$ parts of Koch triangle was associated with a bigger success of the procedure, whereas those located in the upper third had a lower primary success or recurrence [29].

\section{Therapeutic approach}

In figure 6, a therapeutic approach for congenital JET patients is proposed. In those patients with low weight (less than $15 \mathrm{~kg}$ ), cryoablation can only be contemplated when the patient is refractory to pharmacological treatment and hemodynamic decompensation secondary to the arrhythmia, or in the presence of antiarrhythmic side effects. 


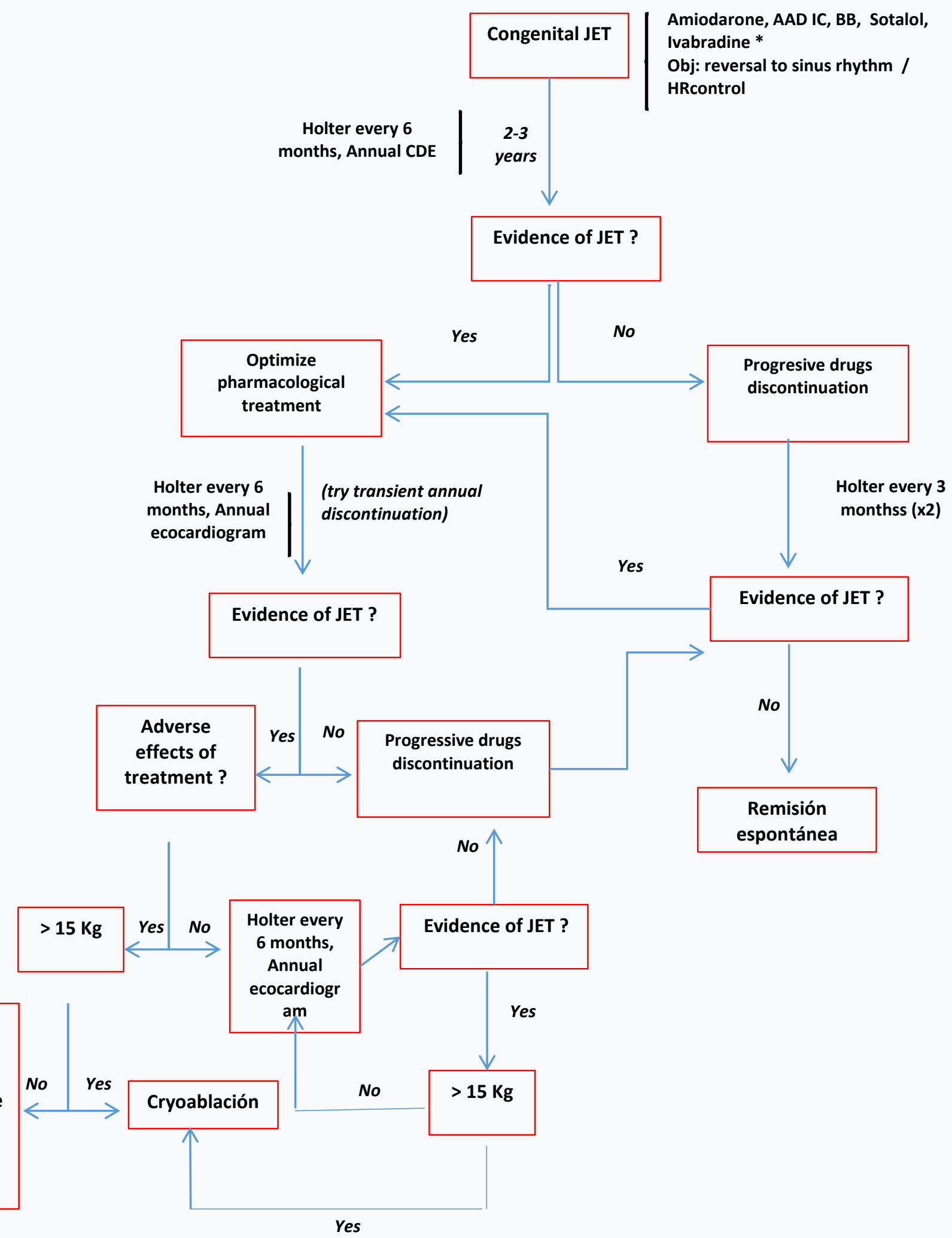

Figure 6: Therapeutic approach.

JET: Junctional Ectopic Tachycardia, AAD: antiarrhythmic drugs, BB: betablocker, 
In those patients over $15 \mathrm{~kg}$, cryoablation can be indicated. As many patients could evolve to spontaneous resolution of congenital JET over time, we believe that cryoablation can be postponed for longer periods of time, if the patient tolerates pharmacological treatment, without side effects. With regards to late onset JET patients, no patient presented spontaneous arrhythmia remission, requiring a cryoablation in all cases $[5,35,36]$.

\section{Conclusion}

Congenital JET is a rare tachycardia and, without an appropriate diagnosis or treatment, it is related to a high morbility and mortality. Currently, there are a wide number of antiarrhythmic drugs that help us control the arrhythmia and get a better prognosis. Development and advances in ablation techniques, particularly in cryoablation and 3D mapping, let us achieve the cure of JET in most cases with low complications.

\section{Conflict of Interest: none}

\section{Reference:}

1. Coumel P, Fidelle JE, Attuel P, Brechenmayer C, Batisse A. et al. (1976) Congenital bundle of His focal tachycardias. Cooperative study of 7 cases, Arch Mal Couer Vaiss. 69:899-909.

2. Villain E, Velter VL, García JM, Herre J, Cifarelli A. (1990) Evolving concepts in the management of congenital junctional ectopic tachycardia. A multicenter study. Circulation. 81:15441549.

3. Collins KK, Van Hare GF, Kertesz NJ, Law IH, Bar-Cohen Y. et al. (2009) Pediatric non post-operative junctional ectopic tachycardia. J Am Coll Cardiol 53:690-697.

4. Sarubbi B, Musto B, Ducceschi V, D'Onofrio A, Cavallaro C, Vecchione $\mathrm{F}$ et al. (2002) Congenital junctional ectopic tachycardia in children and adolescents: a 20 year experience based study. Heart. 88:188-190.

5. Maldonado S, La Fuente V, Benjamin M, Gonzalez Puche E, Huanca Y, Dorme G. et al. (2018) Long-term spontaneous remission of congenital junctional ectopic tachycardia. Rev Argent Cardiol. 86:239-243.

6. Walsh E, Saul P, Sholler GF, Triedman JK, JOnas RA. et al. (1997) Evaluation of a Staged Treatment Protocol for Rapid Automatic Junctional Tachycardia After Operation for Congenital Heart Disease. JACC. 29 (5):1046-1053.

7. Mildh L, Hippala A, Rautiainen P, PettilA V, Sairanen H. (2011) Eur Journal of CArdio - Thoracic Surgery . 75-80.

8. MAkhoul M, Oster M, Fischbach P, Das S, DEshpande S. (2013) Junctional Ectopic Tachycardia after Congenital Heart Surgery inthe current surgical era. Pediatr CArdiol 34:370-374.

9. Zampi JD, Hirsch JC, Gurney JG, Donohue JE, Yu S, Lapage MJ et al. (2012) Junctional Ectopic Tachycardia after infant heart surgery: incidence and outcomes. Pediatr CArdiol. 33: 1362-1369.

10. Bae E-J, Noh Ch-I, Choi J-I, Yun Y-S, Kim W-H, et al. (2005) Late occurrence of Adenosine-sensitive focal Juntional Ectopic Tachycardia in complex congenital heart disease. Jorn Interv Cardiac Electrophisiology 12: 115-122

11. Garson A Jr, Gillette PC. (1979) Junctional ectopic tachycardia in children: electrocardiography, electrophysiology and pharmacologic response. Am J Cardiol 44:298-302.

12. Ruder MA, Davis JC, Eldar M, Abbott JA, Griffin JC, Seger JJ et al. (1986) Clinical and electrophysiology characterization of automatic junctional tachycardia in adults. Circulation 73:930937.

13. Xi Y, Honeywell C, Zhang D, Schwartzentruber J, Beaulieu CL, Tetreault $\mathrm{M}$ et al. (2015) Whole exome sequencing identifies the TNNI3K gene as a cause of familial conduction system disease and congenital junctional ectopic tachycardia. Int J Cardiol. 15; 185:114-116.

14. Villazon E, Fouron JC, Fournier A, Proulx F (2001) Prenatal diagnosis of junctional ectopic tachycardia. Pediatr CArdiol. 22:160-162.

15. Brechenmacher C, Coumel P, James TM. (1976) Intractable tachycardia in infancy. Circulation. 53:377-381.

16. Henneveld H, Hutter P, Bink-Boelkens M, Sreeram N. (1998) Junctional ectopic tachycardia evolving into complete heart block. Heart. 80(6):627-628

17. Wang L, Liang J, Su Ch, Feng Ch, Chen Y, Liu J et al. (2016) The ventriculoatrial relationship after atrial overdrive pacing can help differentiate atrioventricular nodal reentrant tachycardia from junctional tachycardia. J Interv Card Electrophysiol. 47(3):293298.

18. Zaidi SJ, Siddiqui S, Cuneo BF, Strasburger JF, McDuffie R, MD, Wakai RT. et al. (2017) Prenatal diagnosis and management of junctional ectopic tachycardia Heart Rhythm Case Reports, 3:503-508.

19. Paul T, Reimer A, Janousek J, Kallfelz H-C. (1992) Efficacy and safety of propafenone in Congenital Junctional Ectopic Tachycardia. J Am Coll Cardiol 20 (4): 911-914.

20. Benjamin M, Infante J, Olmedo J, Abello M, Moltedo J. (2011) Taquicardia Ectópica Congénita de la Unión: Tratamiento farmacológico en el primer año de vida. Medicina. 71(6): 521-524.

21. Dieks JK, Klehs S, Müller MJ, Paul T, Krause U. (2016) Adjunctive ivabradine in combination with amiodarone: A novel therapy for pediatric congenital junctional ectopic tachycardia. Heart Rhythm. 13:1297-1302.

22. Janson CM, Tan RB, Iyer VR, Vogel RL, Vetter VL. (2019) Ivabradine for treatment of tachyarrhythmias in children and young adults. HeartRhythm Case Rep. Mar 26; 5(6):333-337.

23. Ergul Y, Ozturk E, Ozgur S, Ozyurt A, Cilsal E. (2018) Ivabradine is an effective antiarrhythmic therapy for congenital junctional ectopic tachycardia-induced cardiomyopathy during infancy: Case studies. Pacing Clin Electrophysiol. 41(10):1372-1377.

24. Al-Ghamdi S, Al-Fayyadh MI, Hamilton RM. (2013) Potential new indication for ivabradine: treatment of a patient with congenital junctional ectopic tachycardia. J Cardiovasc Electrophysiol. 24(7):822-824.

25. Dieks JK, MD, Klehs S, Müller MJ, Paul T. et al. (2016) Adjunctive ivabradine in combination with amiodarone: A novel therapy for pediatric congenital junctional ectopic tachycardia. Heart Rhythm. 13:1297-1302.

26. Krishna MR, Kunde MF, Kumar RK, Balaji S. (2016) Ivabradine in Post-operative Junctional Ectopic Tachycardia (JET): Breaking New Ground. Pediatr Cardiol. 2019;40(6):1284-1288.

27. Kumar V, Kumar G, Joshi S, Sharma V. (2017) Ivabradine for junctional ectopic tachycardia in post congenital heart surgery. Indian Heart J. 69(5):666-667

28. Aoki H, Suzuki T, Matsui H, Yasukochi S, Saiki H. (2017) Senzaki HEfficacy of a pure Ikr blockade with nifekalant in refractory neonatal congenital junctional ectopic tachycardia and careful attention to damaging the atrioventricular conduction during the radiofrequency catheter ablation in infancy. HeartRhythm Case Rep. 29; 3(6):298-301.

29. Pierick AR, Law IH, Muldonado JR, Von Bergen NH. (2017) Junctional Ectopic Tachycardia Localization and Procedural Approach using Cryoablation. Pacing Clin Electrophysiol. 40(6):655-660.

30. Law IH, Von Bergen NH, Gingerich JC, Saarel EV, Fishbach PS. et al. (2006) Transcatheter cryothermal ablation of junctional ectopic tachycardia in the normal heart. Heart Rhythm 3:903-907.

31. Wang L, Jiang J, Su C, Feng C, Chen Y, Liu J et al. (2016) The ventriculoatrial relationship after atrial overdrive pacing can help 
differentiate atrioventricular nodal reentrant tachycardia from junctional tachycardia. J Interv Card Electrophysiol. 47(3):293298.

32. Srivathsan K, Gami AS, Barrett R, Monahan K, Packer DL, Asirvatham SJ. (2008) Differentiating atrioventricular nodal reentrant tachycardia from junctional tachycardia: novel application of the delta H-A interval J Cardiovasc Electrophysiol. 19(1):1-6.

33. Padanilam BJ, Manfredi JA, Steinberg LA, Olson JA, Fogel RI. (2008)Differentiating junctional tachycardia and atrioventricular node re-

entry tachycardia based on response to atrial extrastimulus pacin g. J Am Coll Cardiol. 18;52(21):1711-1717
34. Fan R, Tardos JG, Almasry I, Barbera S, Rashba EJ. (2011) Novel

use

of atrial overdrive pacing to rapidly differentiate junctional tachy cardia from atrioventricular nodal reentrant tachycardia. Heart Rhythm. 8(6):840-844.

35. Hamdan M, Badhwar N, Scheinman MM. (2002) Role of Invasive Electrophysiologic Testing in the Evaluation and Management of Adult Patients with Focal Junctional Tachycardia. Cardiac Electrophysiology Review. 6:431-435.

36. Abrams D, Asirvatham S, Bar-Cohen Y, Blaufox AD, Cannon B, Clark J et al. (2009) PACES/HRS expert consensus statement on the use of catheter ablation in children and patients with congenital heart disease. Heart Rhythm 2016; 13 (6): e252-e289.management and interventional therapies. J Am Coll Cardiol 53: 690-697. 